\title{
Cardiac myogenesis: overexpression of XCsX2 or XMEF2A in whole Xenopus embryos induces the precocious expression of XMHC $\alpha$ gene
}

Received: 15 May 1995 / Accepted: 9 August 1995

\begin{abstract}
X C s x 2$, a homeobox-containing gene, is expressed in cardiac muscle during Xenopus development, while the XMEF2A gene is expressed in both cardiac and skeletal muscle. Microinjection of either $X C s x 2$ or $X M E F 2 A$ mRNA into single blastomeres of two-cell stage Xenopus embryos induced precocious expression of the myosin heavy-chain alpha $(X M H C \alpha)$ gene at the neural plate stage (stage 14). Co-injection of both $X C s \times 2$ and $X M E F 2 A$ mRNAs induced still earlier expression at the late gastrula stage (stage 12). These changes were evident in whole embryos but not in animal pole explants from injected embryos. Overexpression of $X C s \times 2$ or $X M E F 2 A$ also caused an enlarged heart and abnormalities of notochord and tail in Xenopus embryos. These findings suggest that both $X C s \times 2$ and $X M E F 2 A$ transcription factors have an important role in regulating the expression of the $X M H C \alpha$ gene and the morphogenesis of heart tissue in Xenopus development.
\end{abstract}

Key words Cardiac myogenesis $\cdot$ Xenopus laevis embryo - Overexpression - XCs $x 2$ and XMEF2A mRNAs $\cdot X M H C \alpha$ gene

\section{Introduction}

Since the discovery of the homeobox motif in genes of the Drosophila homeotic (HOM-C) complex (McGinnis et al. 1984; Scott and Weiner 1984), homeobox genes have been known to play important roles in Drosophila

\section{Y. Fu ${ }^{1}$}

Molecular Medicine Unit, Beth Israel Hospital, and Department of Medicine and Program in Cell and Developmental Biology, Harvard Medical School, Boston, MA 02215, USA

S. Izumo

Cardiovascular Research Center, Department of Internal Medicine, University of Michigan, Ann Arbor, MI 48109, USA

Present address:

${ }^{1}$ Department of Medicine, University of California, San Diego, La Jolla, CA 92093-0613C, USA; Tel.: +1-619-534-7993;

Fax: +1-619-534-8081; e-mail: yuchang-fu@ som-lrc.ucsd.edu segmentation and the elaboration of pattern formation during embryogenesis. Recently, a homeobox gene, tinman, has been reported which encodes a protein required for visceral and cardiac mesoderm formation in Drosophila (Azpiazu and Frasch 1993; Bodmer 1993). Tinman mutants have no visceral or cardiac mesoderm, resulting in an absence of the dorsal vessel, or "heart". These results provide evidence that tinman plays a crucial role in cardiac muscle myogenesis. Homeobox genes are transcription factors which bind to target genes to modulate cell determination and differentiation processes in embryonic development (reviewed by Scott 1994). It is clearly important to find whether they produce their effects on morphogenesis by regulating target genes that are at the upper end of a cascade during embryonic development.

Analysis of Drosophila homeobox genes and discovery of their vertebrate counterparts has provided a useful paradigm for studying the roles of these genes in embryogenesis. Vertebrate homologue of the tinman gene of Drosophila, mouse Cs $x / N k x-2.5$ and Xenopus $X C s \times 2 / X N k x-2.5$ genes have been found to be expressed during cardiac muscle myogenesis (Komuro and Izumo 1993; Lints et al. 1993; Tonissen et al. 1994; Komuro et al., in preparation).

In vertebrate skeletal muscle myogenesis, the MyoD family of transcription factors act as determination factors and regulate the expression of some muscle-specific genes. However, in cardiac muscle myogenesis, very little is known about the determination functions of cardiac-specific transcription factors. Recently, the myocyte enhancer factor 2 (MEF2) transcription factor family has been found in skeletal and cardiac myocytes. There are four $M E F 2$ genes, $M E F 2 A, M E F 2 B, M E F 2 C$ and $M E F 2 D$, which have been isolated from mice (Martin et al. 1993, 1994), and homologues in humans (Pollock and Treisman 1991; Yu et al. 1992; Breitbart et al. 1993; Leifer et al. 1993; McDermott et al. 1993) and frogs (Chambers et al. 1992). MEF2 gene transcripts are detected at high levels in myogenic cells of the myotome and the embryonic heart in mice (Edmondson et al. 1994). The 
expression of the $M E F 2$ gene family in the early heart and somites suggests that these transcription factors may play some important roles in activation of muscle-specific transcription in both cardiac and skeletal muscle and raises the possibility that $M E F 2$ genes could account for the overlapping pattern of gene expression in these two muscle cell types.

Little is currently known about the relationships among $X C s \times 2, X M E F 2 A$, and their target or regulatory genes in muscle myogenesis. We have been interested in investigating the regulatory functions of these two transciption factors using the Xenopus myosin heavy-chain alpha $(X M H C \alpha)$ gene as a marker for cardiac muscle development. As the $X M H C \alpha$ gene transcript is highly enriched in adult heart RNA and embryonically is expressed exclusively in heart tissue, it provides a tissuespecific marker for cardiac muscle differentiation during early embryogenesis (Logan and Mohun 1993). By use of microinjection of synthetic mRNAs into developing embryos, we demonstrate that ectopic expression of $X C S X 2$ and/or $X M E F 2 A$ can induce precocious expression of the $X M H C \alpha$ gene from stage 14 or 12 in whole embryos but not in animal pole explants when either or both mRNAs are injected into early Xenopus embryos. The overexpression of $X C s \times 2$ or $X M E F 2$ also results in an enlarged heart and abnormalities of notochord and tail in injected embryos.

\section{Materials and methods}

Plasmid construction and in vitro transcription

The full-length $X C s x 2 / X N k x-2.5$ (Tonissen et al. 1994) or $X M E F 2 A / S L 2$ (Chambers et al. 1994) cDNA fragment was inserted into EcoRI and XhoI sites of the pSP64RI vector and the DNA sequence confirmed by sequence analyses. To generate sense p64T-XCsx 2 or p64T-XMEF2A transcripts, the p64T-XCsx 2 or p64T-XMEF2A plasmid was digested with SacI and transcribed with SP6 RNA polymerase (Krieg and Melton 1984). For making antisense transcripts, the SK-XCsx2 or SK-XMEF2A plasmid was digested with EcoRI, and SK-XMHC $\alpha$ with PstI, and transcribed with T7 RNA polymerase. The qualities of the synthetic mRNAs were assessed by gel electrophoresis.

\section{Microinjection of embryos}

Specimens of Xenopus laevis were purchased from Xenopus I. Ovulation was induced by injecting 300 U/each of human chorionic gonadotropin (HCG) (Fu et al. 1989). Fertilized eggs were dejellied with $2 \%$ cysteine- $\mathrm{HCl}(\mathrm{pH} 7.8)$ immediately following cortical rotation. For each microinjection experiment, 200 fertilized embryos were injected with $2 \mathrm{ng} / 10 \mathrm{nl}$ of $X C s \times 2$ or $X M E F 2 A$ mRNA at the two-cell stage in $1 \times$ MMR solution (Peng 1991) supplemented with $3 \%$ Ficoll 400 and sodium penicillin and streptomycin sulfate, each at $10 \mathrm{mg} / \mathrm{ml}$. Control injections were performed with $\beta$-galactosidase mRNA. After several cell cycles (about 3-4 h), the embryos were transferred to $0.1 \times$ MMR solution for development. The developmental stages of injected embryos were determined by comparison with non-injected embryos (Nieuwkoop and Faber 1956). Each experiment was performed at least three times.
Dissection of embryos and explant culture

When embryos developed to midblastula stage (stage 8) (Nieuwkoop and Faber 1956), animal poles of the embryos were cut off from the whole embryos in $1 \times$ MMR solution supplemented with $3 \%$ Ficoll 400 and sodium penicillin and streptomycin sulfate, each at $10 \mathrm{mg} / \mathrm{ml}$. The animal pole explants were left in the same solution for $30 \mathrm{~min}$ and then transferred into a culture solution $(0.1 \times$ MMR solution supplemented with some growth factors according to the different experimental purposes). Basic fibroblast growth factor (bFGF; Gibco BRL) was used at a concentration of $200 \mathrm{ng} / \mathrm{ml}$ and transforming growth factor $\beta$ (TGF- $\beta$; Gibco BRL) at $20 \mathrm{ng} / \mathrm{ml}$ in phosphate-buffered saline (PBS) with $0.1 \%$ bovine serum albumin (BSA). Activin A was used at $50 \mathrm{U} / \mathrm{ml}$. After the explants were cultured for $36 \mathrm{~h}$ (stage 35 ), they were collected for assay of $X M H C \alpha$ transcripts.

\section{RNA extraction and RT-PCR assays}

Ten animal pole explants or eight embryos were extracted with RNA extraction buffer $(0.1 \mathrm{M}$ Tris, $0.5 \%$ SDS, $0.1 \mathrm{M} \mathrm{NaCl}, 0.01$ M EDTA and $150 \mu \mathrm{g} / \mathrm{ml}$ Proteinase K). The RNA samples were treated with RQ1 RNase-Free DNase (Promega), and cDNAs were synthesized with SuperScript II RNaes H-reverse transcriptase (RT; Gibco BRL) at $45^{\circ} \mathrm{C}$ for $2 \mathrm{~h}$ with RNA extracted from ten animal pole explants or eight embryos. A tenth part volume of the transcription reaction solution was used for a polymerase chain reaction (PCR) with Vent DNA polymerase (New England Biolabs). The sequences of the primers used were: $X M H C \alpha: 5^{\prime}$ primer, CA CGA GCT GGA TGA GGC TG; 3' primer, AG TGC TGA ATT T AA TGG TC. Elongation factor- $1 \alpha(\mathrm{EF}-1 \alpha): 5^{\prime}$ primer, CCT GAA TCA CCC AGG CCA GAT TGG TG; 3' primer, GAG GGT AGT CTG AGA AGC TCT CCA CG. The conditions for PCR were: $94^{\circ} \mathrm{C}$ for $3 \mathrm{~min}$, annealing at $55^{\circ} \mathrm{C}$ for $1.5 \mathrm{~min}$ and elongation at $72^{\circ} \mathrm{C}$ for $1 \mathrm{~min}$, followed by 24 cycles at $94^{\circ} \mathrm{C}$ for $1 \mathrm{~min}$, at $55^{\circ}$ $\mathrm{C}$ for $1.5 \mathrm{~min}$ and at $72^{\circ} \mathrm{C}$ for $1 \mathrm{~min}$.

In situ hybridization and histology

Whole-mount in situ hybridization was performed according to Harland (1991). Embryos for sectioning were fixed with $4 \%$ paraformaldehyde at $4^{\circ} \mathrm{C}$ overnight. Embryo sections were stained with eosin (Kelly et al. 1991).

\section{Results and discussion}

Induction of early expression of the $X M H C \alpha$ gene in the whole Xenopus embryo by overexpression of $X C s \times 2$ or $X M E F 2 A$

In mouse embryogenesis, Csx and $M E F 2$ genes begin to be expressed in cardiac primordia around 7.5 days post coitum, at a stage when the primordial heart is simply a region of thickened splanchnic mesoderm. Csx and $M E F 2$ genes are the earliest known markers of vertebrate heart development, and these transcription factors may play important roles for cardiac muscle differentiation (Bodmer 1995). Although it is still not known whether there is a relationship between $C s x$ and $M E F 2$ genes, it is possible that these transcription factors have some same or similar functions in early muscle cell differentiation. In this paper, we have used $X M H C \alpha$ as a marker gene to investigate interactions between $X C s \times 2$ or $X M E F 2 A$ and the $X M H C \alpha$ gene in developing Xenopus embryos. 
Embryo Stage

$\begin{array}{lllllll}8 & 12 & 14 & 18 & 26 & 35 & 42\end{array}$

A

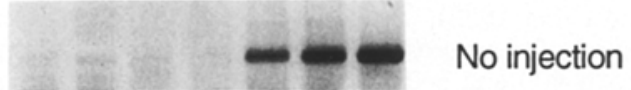

B

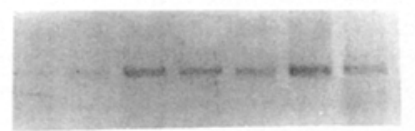

XCsx2 injected

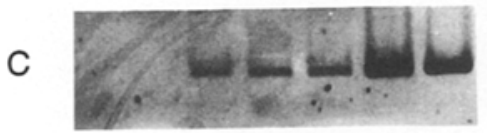

XMEF2A injected

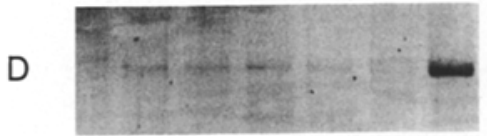

$\mathrm{XCs} \times 2$ and $\mathrm{XMEF} 2 \mathrm{~A}$ Co-injected

E

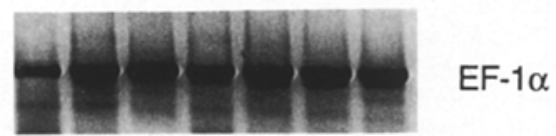

Fig. 1 RT-PCR assays demonstrate different expression patterns of the $X M H C \alpha$ gene in normal and injected Xenopus embryos during development. A The expression of the $X M H C \alpha$ gene was examined at different developmental stages of non-injected normal embryos: stage 8 (midblastula), stage 12 (late gastrula), stage 14 (neural plate), stage 18 (neural groove), stage 26 (tailbud), stage 35 (late tailbud), and stage 42 (tadpole). XMHC $\alpha$ gene expression was detected from stage 26 onward. B After injection of XCs $x 2$ mRNA, expression of the $X M H C \alpha$ gene was detected from stage 14. C As with the XCs $\times 2 \mathrm{mRNA}$ injection experiment, injecting $X M E F 2 A$ mRNA induced expression of the $X M H C \alpha$ gene from stage 14 in whole embryos. D Yet earlier expression of the $X M H C \alpha$ gene, from stage 12, was detected after co-injection of $X C s x 2$ and $X M E F 2 A$ mRNAs. E Expression of the EF- $1 \alpha$ gene as an internal control for amounts of RNA in $\mathbf{D}$ for different stages of Xenopus embryos.

In order to investigate the relationship between $X C s \times 2$ or $X M E F 2 A$ transcription factors and contractile muscle gene expression, we microinjected mRNAs for the transcription factors into two-cell stage Xenopus embryos and examined the expression of the $X M H C \alpha$ gene during embryonic development by RT-PCR assays. In non-injected embryos, the $X M H C \alpha$ gene is first expressed at the tailbud stage (stage 26) (Logan and Mohun 1993; and Fig. 1A). However, when either $X C s \times 2$ or $X M E F 2 A$ mRNA was injected into two-cell stage Xenopus embryos, the expression of the $X M H C \alpha$ gene was induced from stage 14 in whole embryos (Fig. 1B, C). As injection of either $X C s \times 2$ or $X M E F 2 A$ mRNA induced the early expression of $X M H C \alpha$ gene in the whole embryo, we wanted to examine the effect of co-injection of both $X C s \times 2$ and XMEF2A mRNAs into two-cell stage Xenopus embryos. Expression of $X M H C \alpha$ gene after co-injection was observed from stage 12 rather than from stage 14 in the whole embryo (Fig. 1D). However, expression of the $X M H C \alpha$ gene after co-injection was lower than injection of either $X C s \times 2$ or $X M E F 2 A$ mRNA alone. This may reflect a regulatory interaction between $X C s \times 2$ and
$X M E F 2 A$ affecting $X M H C \alpha$ gene regulation. The RTPCR signal obtained for $X M H C \alpha$ gene expression (Fig. 1D) was normal, evaluated from the signal obtained for elongation factor- $1 \alpha$ (EF-1 $\alpha$; Fig. $1 \mathrm{E})$.

These results from ectopic overexpression of $X C s x 2$ and $X M E F 2 A$ indicated that both can induce the precocious expression of the XMHC $\alpha$ gene in Xenopus embryo development, suggesting that these transcription factors may play an important role in cardiac muscle myogenesis.

Animal cap experiments were also performed. Following injection of $X C s \times 2$ or XMEF $2 A$ mRNA into twocell stage embryos, animal poles were explanted at stage 8 and cultured until stage 35 . No expression of the $X M H C \alpha$ gene was detected in animal pole explants with various injection doses of $X C S X 2$ or XMEF $2 A$ mRNA, co-injection of $X C s X 2$ and $X M E F 2 A$ mRNAs, or injection of these mRNAs with combinations of treatment with different growth factors, including bFGF, TGF- $\beta$ and Activin A (data not shown). The inability of injected $X M E F 2 A$ mRNA to induce expression of $X M H C \alpha$ gene in animal pole explants confirms the findings of previous investigators (Chambers et al. 1994). These results suggest that $X C s \times 2$ and $X M E F 2 A$ regulate expression of $X M H C \alpha$ gene with unknown cofactor(s) in mesoderm or endoderm which are not present in animal caps explanted at the midblastula stage (stage 8).

Enlarged hearts and abnormalities of notochord and tail in embryos with ectopic overexpression of $X C s x 2$ or $X M E F 2 A$

After embryos were injected with $X$ Cs $x 2$ or $X M E F 2 A$ mRNA, they began to develop abnormally at late gastrulation. At stage 12, the embryos injected with $X C s \times 2$ or $X M E F 2 A$ mRNA had larger yolk plugs than control embryos. From stage 14, the neural fold in experimental embryos did not close, exposing inner dorsal cells until late stages. Whole-mount in situ hybridization analysis was used to examine $X M H C \alpha$ transcripts in late tailbud stage embryos. Injection of $X M E F 2 A$ mRNA resulted in more severe abnormalities than injection of $X C s \times 2 \mathrm{mR}$ NA, as indicated by the length of the embryonic body; the embryos developed an abnormal notochord and tail phenotype with enlarged hearts (Fig. 2C E). These features were not observed in control embryos which had been injected with $\beta$-galactosidase mRNA (Fig. 2A). Among surviving embryos, about $70 \%$ injected with $X M E F 2 A$ mRNA or co-injected with $X C s \times 2$ and $X M E F 2 A$ mRNAs, and about $50 \%$ injected with $X C_{s} \times 2$ mRNA, had the abnormal phenotype (Table 1).

In order to examine the effect on embryos injected with $X C s x 2$ or $X M E F 2 A$ mRNA in more detail, wholemount stained embryos were longitudinally sectioned. The enlarged heart observed in the XMEF2A mRNA-injected embryos was evident (Fig. 2D) on comparison with the heart in the $\beta$-galactosidase mRNA-injected embryos (Fig. 2B). The findings were the same in embryos which were injected with $X C s \times 2$ mRNA or co-injected with $X C s \times 2$ and $X M E F 2 A$ mRNAs (data not shown). 

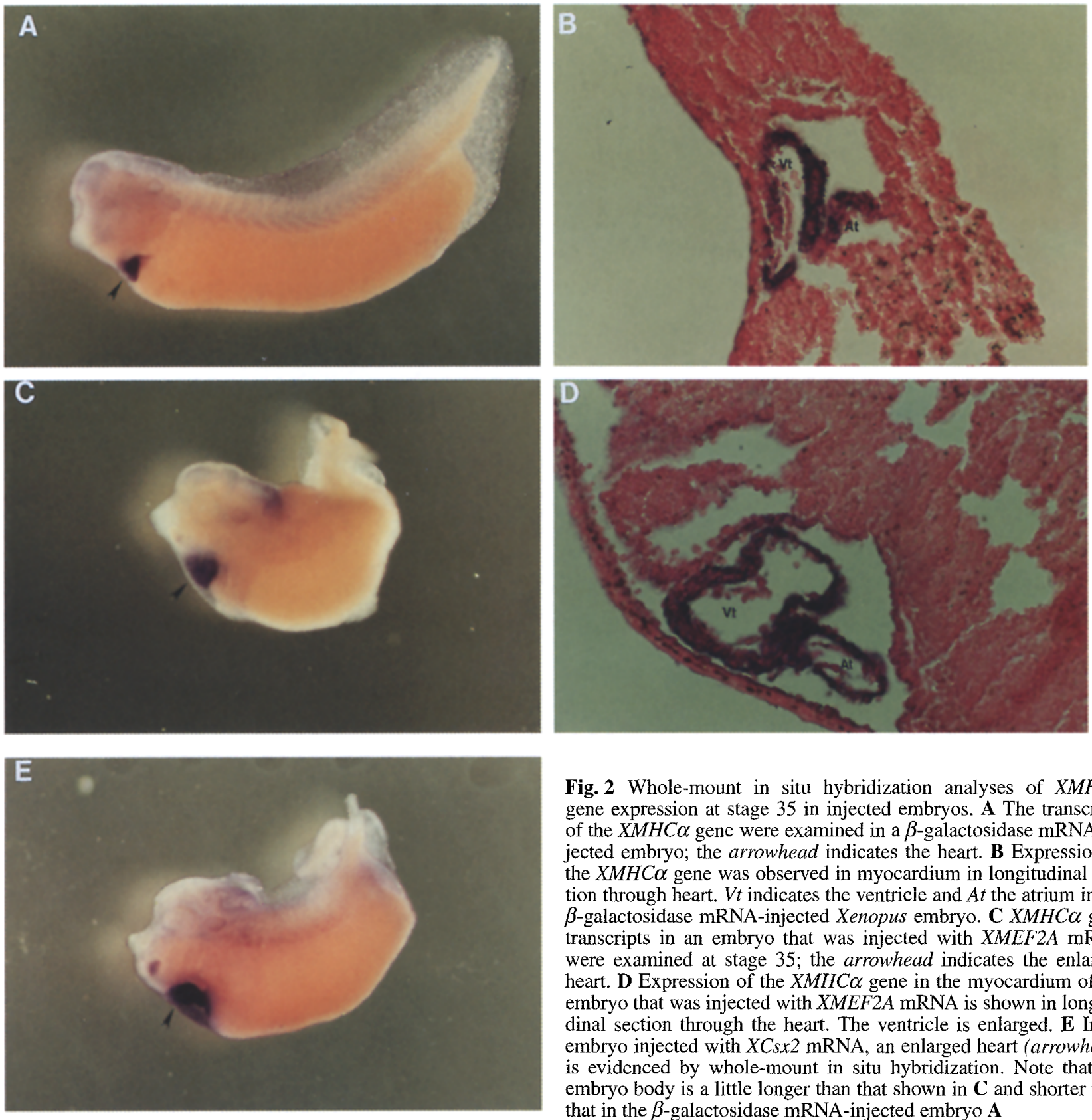

Fig. 2 Whole-mount in situ hybridization analyses of $X M H C \alpha$ gene expression at stage 35 in injected embryos. A The transcripts of the $X M H C \alpha$ gene were examined in a $\beta$-galactosidase mRNA-injected embryo; the arrowhead indicates the heart. B Expression of the $X M H C \alpha$ gene was observed in myocardium in longitudinal section through heart. $V t$ indicates the ventricle and $A t$ the atrium in the $\beta$-galactosidase mRNA-injected Xenopus embryo. C XMHC $\alpha$ gene transcripts in an embryo that was injected with $X M E F 2 A$ mRNA were examined at stage 35 ; the arrowhead indicates the enlarged heart. D Expression of the $X M H C \alpha$ gene in the myocardium of the embryo that was injected with $X M E F 2 A$ mRNA is shown in longitudinal section through the heart. The ventricle is enlarged. $\mathbf{E}$ In an embryo injected with $X C s \times 2 \mathrm{mRNA}$, an enlarged heart (arrowhead) is evidenced by whole-mount in situ hybridization. Note that the embryo body is a little longer than that shown in $\mathbf{C}$ and shorter than that in the $\beta$-galactosidase mRNA-injected embryo $\mathbf{A}$

Table 1 The number of embryos used in experiments for injection of different mRNAs. Embryos were injected with $5 \mathrm{ng}$ of mRNA at the two-cell stage and raised to stage 35 (late tailbud) for check-

ing the phenotype. The abnormal phenotype includes a split notochord and neural tube and a truncated tail. The values are averages from three independent experiments

\begin{tabular}{lllcl}
\hline mRNA injected & No. of embryos & Phenotype normal (\%) & Phenotype abnormal (\%) & Died (\%) \\
\hline$\beta$-Gal & 200 & $187(93.5)$ & $2^{\text {a }}(1.0)$ & $11(5.5)$ \\
$X$ Csx2 & 200 & $63(31.5)$ & $68(34.0)$ & $69(34.5)$ \\
$X M E F 2 A$ & 200 & $36(18.0)$ & $94(47.0)$ & $70(35.0)$ \\
$X$ CSS2+XMEF2A & 200 & $45(22.5)$ & $89(44.5)$ & $66(33.0)$ \\
\hline
\end{tabular}

a Nonspecific sacculated abdomen

The abnormal phenotype caused by overexpression of $X C s \times 2$ and/or $X M E F 2 A$ was observed from stage 12. At this stage in normal embryo development, mesodermal and endodermal cells are migrating toward the animal pole, involution on the dorsal side has advanced, and a small yolk plug is present on the embryos. However, in experimental embryos, larger yolk plugs were observed at stage 12 , possibly resulting in a split notochord. It may be that overexpression of $X C s \times 2$ or $X M E F 2 A$ retards the movements of mesodermal and endodermal cells dur- 
ing the cellular involution which occurs during gastrulation. Perhaps as a result of the abnormal movements, closure of the neural folds was delayed during neurulae stages, which could account for the truncated tail. Recently, it has been reported that treatment of cleavage stage embryos with lithium increases the heart tissue but interferes with migration of the primordia to the ventral midline for fusing to form the mature heart, which does not appear to be enlarged (Drysdale et al. 1994). In view of our finding that ectopic overexpression of $X C s \times 2$ or $X M E F 2 A$ resulted in enlarged hearts, the mechanism probably differs from that of lithium treatment. Ludolph et al. (1994) recently reported that overexpression of $X M Y o D$ and $X M y f 5$ causes the formation of enlarged myotomes through recruitment of cells of nonsomitic lineage rather than by an increase in muscle precursor cell division. It will be of interest to investigate whether a similar mechanism is operative in the heart enlargement found in our study.

Acknowledgements We thank Dr. Sergei Sokol for pSP64RI vector and Activin A, Dr. Sylvia Evans for critical reading of the manuscript. S.I. is an Established Investigator of the American Heart Association.

\section{References}

Azpiazu N, Frasch M (1993) Tinman and bagpipe: two homeobox genes that determine cell fates in the dorsal mesoderm of Drosophila. Genes Dev 7:1325-1340

Bodmer R (1993) The gene tinman is required for the specification of the heart and visceral muscles in Drosophila. Development 118:719-729

Bodmer R (1995) Heart development in Drosophila and its relationship to vertebrates. Trends Cardiovasc Med 5:21-28

Breitbart R, Liang C, Smoot L, Laheru D, Mahdavi V, Nadal-Ginard B (1993) A fourth human MEF-2 transcription factor, hMEF2D, is an early marker of the myogenic lineage. Development 118:1095-1106

Chambers AE, Kotecha S, Towers N, Mohun TJ (1992) Musclespecific expression of SRF-related genes in the early embryo of Xenopus laevis. EMBO J 11:4981-4991

Chambers AE, Logan M, Kotecha S, Towers N, Sparrow D, Mohun TJ (1994) The RSRF/MEF2 protein SL1 regulates cardiac muscle-specific transcription of a myosin light-chain gene in Xenopus embryos. Genes Dev 8:1324-1334

Drysdale TA, Tonissen KF, Patterson KD, Crawford MJ, Krieg PA (1994) Cardiac troponin I is a heart-specific marker in the $\mathrm{Xe}$ nopus embryo: expression during abnormal heart morphogenesis. Dev Biol 165:432-441

Edmondson DG, Lyons GE, Martin JF, Olson EN (1994) Mef2 gene expression marks the cardiac and skeletal muscle lineages during mouse embryogenesis. Development 120:1251-1263

Fu Y, Hosokawa K, Shiokawa K (1989) Expression of circular and linearized bacterial chloramphenicol acetyltransferase genes with or without viral promoters after injection into fertilized eggs, unfertilized eggs and oocytes of Xenopus laevis. Rouxs Arch Dev Biol 198:148-156

Harland RM (1991) In situ hybridization: an improved whole mount method for Xenopus embryos. In: Kay BK, Peng HB (eds) Xenopus laevis: practical uses in cell and molecular biology. Academic Press, London, pp 685-695

Kelly GM, Eib DW, Moon RT (1991) Histological preparation of Xenopus laevis oocytes and embryos. In: Kay BK, Peng HB (eds) Xenopus laevis: practical uses in cell and molecular biology. Academic Press, London, pp 389-417

Komuro I, Izumo S (1993) Csx: a murine homeobox-containing gene specifically expressed in the developing heart. Proc Natl Acad Sci USA 90:8145-8149

Krieg PA, Melton DA (1984) Functional messenger RNAs are produced by SP6 in vitro transcription of cloned cDNAs. Nucleic Acids Res 12:7057-7070

Leifer D, Krainc D, Yu Y-T, McDermott J, Breitbart RE, Heng J, Neve RL, Kosofsky B, Nadal-Ginard B, Lipton SA (1993) MEF2C, a MADS/MEF2-family transcription factor expressed in a laminar distribution in cerebral cortex. Proc Natl Acad Sci USA 90:1546-1550

Lints TJ, Parsons LM, Hartley L, Lyons I, Harvey RP (1993) Nkx2.5: a novel murine homeobox gene expressed in early heart progenitor cells and their myogenic descendants. Development 119:419-431

Logan M, Mohun TJ (1993) Induction of cardiac muscle differentiation in isolated animal pole explants of Xenopus laevis embryos. Development 118:865-875

Ludolph DC, Neff AW, Mescher AL, Malacinski GM, Parker MA, Smith RC (1994) Overexpression of XMyoD or Xmyf5 in Xenopus embryos induces the formation of enlarged myotomes through recruitment of cells of nonsomitic lineage. Dev Biol $166: 18-33$

Martin JF, Schwarz JJ, Olson EN (1993) Myocyte enhancer factor (MEF) 2C: a tissue-restricted member of the MEF-2 family of transcription factors. Proc Natl Acad Sci USA 90: $5282-5286$

Martin JF, Miano JM, Hustad CM, Copeland NG, Jenkins NA, Olson EN (1994) A Mef2 gene that generates a muscle-specific isoform via alternative RNA splicing. Mol Cell Biol $14: 1647-1656$

McDermott J, Cardoso M, Yu Y-T, Andres V, Leifer D, Krainc D, Lipton SA, Nadal-Ginard B (1993) hMEF2C gene encodes skeletal muscle- and brain-specific transcription factors. Mol Cell Biol 13:2564-2577

McGinnis M, Garber RL, Wirz J, Kuroiwa A, Gegring W (1984) A homologous protein-coding sequence in Drosophila homeotic genes and its conservation in other metazoans. Cell 37:403-408

Nieuwkoop P, Faber J (1956) Normal table of Xenopus laevis (Daudin). North-Holland, Amesterdam

Peng HB (1991) Solutions and protocols. In: Kay BK, Peng HB (eds) Xenopus laevis: practical uses in cell and molecular biology. Academic Press, London, pp 657-662

Pollock R, Treisman R (1991) Human SRF-related proteins: DNAbinding properties and potential regulatory targets. Genes Dev 5:2327-2341

Scott MP (1994) Intimations of a creature. Cell 79:1121-1124

Scott MP, Weiner AJ (1984) Structural relationships among genes that control development: sequence homology between the $A n$ tennapedia, Ultrabithorax and fushi tarazu loci of Drosophila. Proc Natl Acad Sci USA 81:4115-4119

Tonissen KF, Drysdale TF, Lints TJ, Harvey RP, Krieg PA (1994) $X N k x-2.5$, a Xenopus gene related to $N k x-2.5$ and tinman: evidence for a conserved role in cardiac development. Dev Biol $162: 325-328$

Yu Y, Breitbart R, Smoot L, Lee Y, Mahdavi V, Nadal-Ginard B (1992) Human myocyte specific enhancer factor 2 (MEF2) comprises a group of tissue restricted MADS box transcription factors. Genes Dev 6:1783-1798 